\title{
Textos
}

\author{
MARIA JOSÉ GÁMEZ FUENTES ${ }^{1}$
}

\section{Cinematergrafía. La madre en el cine y la literatura de la democracia. ${ }^{2}$}

En este marco es en el que se puede leer la utilización de lo materno en las narrativas analizadas: como una figura que articula en el imaginario cultural español los problemas alrededor de los vínculos y rupturas entre dictadura y democracia. La fuerte focalización retórica sobre tal rol en la dictadura habría provocado una sobreinversión de contenido histórico-político en posteriores representaciones democráticas. Por otro lado, los procesos de identificación creados durante el franquismo, como procesos que son, no pueden acabar en un momento concreto como es la muerte del dictador. A partir de esa hiperretorización, la maternidad aparece anclada en la cultura española como nudo representativo que ocupa un lugar fundamental para el entendimiento de nuestra cultura. Es en ese contexto en el que se encuadran las continuidades representativas: cuando la madre aparece no solo se está hablando de una madre sino del pasado y su relación con el presente.

La problemática galería de representaciones maternas que hemos encontrado intentan exponer las particulares reinscripciones por parte de la retórica franquista (Furtivos y Cría cuervos), la falacia de su extendida e incontestada sumisión (ídem), su relevancia en la búsqueda de nuevos discursos democráticos (El mismo mar, Gary Cooper y El pájaro) y la posibilidad de reescribir un legado dictatorial alternativo al construido por la amnesia democrática (Nubosidad, Mujeres y Nadie hablará). Este proceso ha estado reforzado durante la democracia por los emergentes discursos sobre las mujeres, los cuales se han propuesto una revisión de la conexión de estas con el ámbito de la cultura a través de los textos (en el sentido más general de la palabra) que han moldeado/incardinado sus posicionamientos. Esta revisión ha tenido como resultado un específico intento de mirar al pasado dictatorial y al presente democrático mediante una recuperación de un legado matrilineal que ayude a las mujeres a cuestionar las narrativas que las interpelan en diferentes entornos histórico-subjetivos actuales.

Ahora bien, lo que cambia y lo que permanece se traduce en los variados puntos de inflexión que caracterizan las diferentes representaciones que hemos ido abordando. Estos puntos se construyen sobre dos ejes: el eje de la discontinuidad que marca las diferencias entre las diversas representaciones de lo materno como abyección o amenaza que ha de ser expulsada (Fugitivos y Cría cuervos), marginalidad

1 Profesora de la Universitat Jaume I de Castellón.

2 Este texto está extraído del libro del mismo nombre publicado en la editorial Sendes de la Universitat Jaume I. 
(El mismo mar, Gary Cooper y El pájaro) y heterodoxia (Nubosidad, Mujeres y Nadie hablará); el eje de la continuidad, el cual establece los vínculos entre las diferentes representaciones como diversos momentos de un mismo proceso, a saber:

a) Con Furtivos y Cría cuervos asistimos a una deformación del discurso franquista sobre la maternidad por exceso y por defecto respectivamente. La conceptualización de lo materno se presenta como figura abyecta que amenaza la integridad de los protagonistas en ambas películas. Esta conceptualización está atrapada en la retórica franquista, que constituye como únicos posicionamientos para la mujer la maternidad todopoderosa (Furtivos) o abnegada y sacrificada (Cría cuervos). Estas visiones de la mujer están influenciadas por la inmediatez del pasado dictatorial, con la enorme carga ideológica proyectada sobre la maternidad como personificación de la España franquista, y por la incertidumbre ante la viabilidad de una ruptura democrática. A través de las madres de las dos películas elegidas se intenta conjurar el espectro del franquismo.

b) Por otro lado, surgen narrativas que intentan alejarse de todo lo que el franquismo significó. Es en este sentido en el que se puede leer la marginación de lo materno en El mismo mar, Gary Cooper, El pájaro, donde la maternidad se presenta no como figura central sino como aparentemente tangencial. En la novela y las dos películas se reitera un intento de construcción narrativa basada en la exclusión retórica de la experiencia franquista, la cual se representa en forma de madre represora o alejada de las necesidades de la siguiente generación. La amenaza de la madre abyecta de la dictadura se ha desplazado aquí a los márgenes narrativos, intentando desatender de esta forma la amenaza que encerraba. La lejanía y falta de comprensión de las voces narrativas hacia la madre epitoman la amnesia democrática que se resisten a mirar al pasado de otra forma, o incluso a mirar a otro pasado. Este desplazamiento provoca, no obstante, el oscurecimiento de un conjunto de variables residuales que siguen operando durante la democracia. El foco de estos textos son, pues, las nuevas situaciones surgidas en este período. Asistimos a una búsqueda dentro de otras narrativas, tanto democráticas como occidentales, aparentemente alejadas del pasado dictatorial, en las que las variables a tener en cuenta exponen una diversidad geográfica, social y generacional que no siempre tiene cabida en las narrativas de legitimación de la socialdemocracia. Las fricciones que las obras analizadas encierran se originan tanto en la convergencia de las diversas coordenadas en juego como en la escasez de alternativas para vincularse como el pasado franquista y el presente democrático de una forma no hegemónica. La legitimación de diferentes colectivos que intentan negociar sus posicionamientos se realiza, así, respecto a y, también contra las narrativas de un nuevo estado de derecho.

c) Nubosidad, Mujeres y Nadie hablará se proponen por medio de la recuperación pendular de la figura de la madre heterodoxa no solo formas alternativas de mirar al pasado sino la recuperación del legado de otro pasado exiliado de la memoria democrática que ayude a las actuales generaciones a comprender sus posiciones en nuevo régimen. La maternidad del período franquista no es aquí sinónimo de dictadura. El proyecto de estas narrativas pasa por reconocer la relevancia de otras 
madres durante el franquismo, la posibilidad de un legado matrilineal disidente y los residuos (liberadores $\mathrm{u}$ obstaculizadores) con que las nuevas generaciones han de negociar sus propias posiciones en la democracia. Se intenta resucitar, de esta forma, la figura de la madre, pero no a través de la expulsión ni de la marginalización, sino revalorizando su complejidad y revisando el destierro al que se la ha relegado, para así poder construir una posición crítica en y desde el presente. Estos proyectos son obviamente parciales puesto que las visiones que ofrecen no pueden abarcar todas las coordenadas sociales. No obstante sus reescrituras insinúan vías de renovación discursiva a través de las que los sujetos pueden construir posiciones agentes en y contra las narrativas hegemónicas. Su importancia reside en el intento de mostrar y dislocar los procesos mismos de narratividad cultural a través de diversas estrategias, a saber; la autoconsciencia de escritura multivocal y la fragmentación textual (Nubosidad), la autobiografía de revisión pendular histórico-subjetiva y la memoria exiliada (Mujeres) y la mezcla sincrónica y diacrónica de convenciones narrativas (Nadie hablará). En particular Nadie hablará complejiza esta cuestión al introducir lo materno en la reescritura de un thriller de tonos españoles que pone de relieve el rol de las narrativas culturales (anunciada ya en las revistas femeninas y las carteleras publicitarias de Cría cuervos y la referencia a TVE en Gary Cooper) en los procesos de identificación y narrativización históricosubjetiva. Por otro lado, se reivindica la posibilidad de utilizar la fragmentación y pastiche postmodernistas en una crítica social sobre los residuos de las narrativas franquistas en las democráticas, de las narrativas exiliadas en las hegemónicas.

Esos tres momentos de configuración de lo materno exploran, por otro lado, diversas temáticas que constituyen los diferentes trazos del eje de discontinuidad histórica:

a) Furtivos presenta una crítica por exceso a la construcción discursiva de la madre fálica mediante la representación de Martina. Los supuestos poderes que la madre parece tener dentro de la retórica franquista son magnificados mediante la construcción exagerada de una madre fálica con aparentemente completo control sobre su hijo. Esta madre rural intenta abrazar ferozmente la ilusoria posición de sujeto que ofrece el modelo de madre todopoderosa identificada con la patria en el franquismo. Su fracaso, en cambio, expone la falta de control que el personaje tiene sobre el lugar en el que la dictadura le ha interpelado. Cría cuervos, por otra parte, presenta una crítica por defecto. Abnegación y sacrificio se reducen a la mínima expresión en el papel ausente (fantasmal) de María, una madre que estuvo exclusivamente dedicada a la casa y a sus hijas. La ausencia de la madre crítica, en este caso, cómo el ideal de la maternidad enarbolado por la retórica franquista construía una posición histórica y simbólicamente castrante para las mujeres, puesto que ese ideal de Madre sacrificada anulaba la existencias de las madres como sujetos.

b) El mismo mar explora la relevancia de la figura materna en la búsqueda de nuevos posicionamientos que ayuden a la protagonista a desmarcarse de las narrativas de la economía heterosexual y de clase alta barcelonesa. Su objetivo es poder articular un deseo femenino de forma no alienante y no perpetuadora de los 
estereotipos establecidos. Gary Cooper y El pájaro tratan los problemas emergentes entre los nuevos discursos y libertades de la mujer y los antiguos valores, las nuevas posibilidades de acceso laboral, la persistencia de los estereotipos sobre la maternidad y feminidad y la maternidad como obstáculo de la mujer profesional. En el contexto de la reconstrucción democrática los tres textos presentan tensiones comunes: confusión de valores y desencanto y marginalidad de ciertos grupos (homosexuales, inmigrantes, gitanos, mujeres de clase trabajadora), cuya visibilidad está supeditada al estatus instrumental que adquieren en las narrativas analizadas. Esas tensiones traducen los problemas inherentes a la unificación de un proyecto de reconstrucción nacional que: oblitera y/o instrumentaliza variables de clase social, de origen geográfico o étnico, simplifica e idealiza la identidad sexual (cuando se sale de los parámetros de la heterosexualidad) y tipifica y reduce los procesos que conforman la relación del sujeto masculino con la cultura.

c) Nubosidad presenta una diferencia sustancial respecto a las narrativas analizadas en este trabajo y es la posibilidad de voz materna. Sofía subvierte la posición de interlocutora silenciosa de anteriores narrativas y asume la voz, mejor dicho la pluma, en la escritura de su propio texto. La pluralidad de voces femeninas recoge un paisaje social en el que se recupera tanto otra visión de lo materno como otro pasado materno, representado en la resurrección onírica de su propia madre. La memoria de/en Mujeres subraya la relevancia del pasado, la conexión de las historias exiliadas con la Historia y los vínculos de la memoria exiliada de personajes desmarcados de la oficialidad con la narrativa hegemónica. Se perpetúa, así, la idea de que el exilio siempre es recíproco y de que existe dependencia entre lo que se intenta exiliar y las narrativas vigentes en que se opera el exilio. El tema del exilio es explorado en diferentes grados en una espiral de círculos concéntricos que van desde el exilio histórico al exilio de la madre pasando por una reivindicación de tal posición como disidente. La narrativa de Juana, la hija, retoma el legado narrativo materno en un intento de luchar contra el silencio al que diversas voces femeninas fueron relegadas tanto en el franquismo como en la memoria democrática. Frente al desencanto de los ochenta esos dos textos ofrecen esperanzadoras renovaciones discursivas. La crítica social que llevan a cabo se complementa con Nadie hablará, la cual recupera la figura materna comprometida políticamente en un proyecto narrativo que explora los residuos de narrativas pasadas para una crítica de situaciones de violencia social y simbólica presentes. En definitiva, frente al impulso centrípeto de las narrativas hegemónicas, lo materno aparece en los textos analizados en el capítulo 6 como espacio generador de vectores de resistencia centrífuga. Posibilita la construcción crítica de narrativas disonantes respecto al pasado y al presente en un movimiento pendular que revaloriza lo que se intenta desterrar. Este potencial no deja de generar ecos, como indican las publicaciones de Quadern d'espera (Riera, 1998) y Sangre de mi sangre (Regàs, 1998), donde la madre vuelve a asumir la voz narrativa, y las producciones de Solas (Zambrano, 1999), sobre la madre rural, y de Todo sobre mi madre (Almodóvar, 1999), como hemos visto. 